\title{
Cavernous Malformation of the Hypoglossal Nerve: Case Report and Review of the Literature
}

\author{
Michael Chow, Bassam Addas, Virgilio Sangalang, Renn Holness
}

\begin{abstract}
Objective: To describe a patient who presented with a hypoglossal nerve palsy caused by a cavernous malformation, review the literature on cavernous malformations associated with cranial nerves and the differential diagnosis of hypoglossal palsy. Results: Partial resection of the lesion was achieved and the diagnosis of cavernous malformation proven histologically. Conclusions: Involvement of a cranial nerve by a cavernous malformation is very uncommon and the facial nerve is the example most frequently reported. This case report adds another possible site for this rare occurrence.
\end{abstract}

RÉSUMÉ: Malformation caverneuse du nerf hypoglosse: observation de cas et revue de la littérature. Objectif: Nous décrivons le cas d'un patient qui a présenté une paralysie du nerf hypoglosse causée par une malformation caverneuse et nous revoyons la littérature sur les malformations caverneuses associées aux nerfs crâniens ainsi que le diagnostic différentiel de la paralysie du nerf hypoglosse. Résultats: Une résection partielle de la lésion a été effectuée et le diagnostic de malformation caverneuse a été confirmé en anatomopathologie. Conclusions: l'atteinte d'un nerf crânien par une malformation caverneuse est très rare et l'atteinte du nerf facial est l'exemple le plus souvent rapporté. Cette observation décrit un autre site possible de cette pathologie rare.

Can. J. Neurol. Sci. 2002; 29: 191-194

Cavernous malformation accounts for $8-16 \%$ of all intracranial vascular malformations. ${ }^{1}$ They have been variably called cavernous hemangiomas, cavernous angiomas and cavernomas and represent a subset of angiographically occult vascular malformations. Intracranially, they most commonly occur in the cerebrum but are also known to occur in the brain stem, cerebellum and, rarely, in association with cranial nerves. ${ }^{1}$

By definition, cavernous malformations are wellcircumscribed benign vascular lesions composed of sinusoidal vascular channels devoid of any intervening neural parenchyma. ${ }^{2}$ In this report we describe the unique case of a cavernous malformation associated with the hypoglossal nerve and review the literature on involvement of other cranial nerves by these lesions.

\section{Case Report}

A 32-year-old woman presented with a four-year history of accidentally biting the right side of her tongue. For the previous year, she had also noted that her tongue deviated to the right and she had developed a lisp in her speech. There was no history of dysphagia, hoarseness or hearing loss.

On examination, there was a noticeable lisp in her speech. There was significant wasting accompanied by fasciculations on the right half of the tongue. Tongue deviation to the right was also observed. The rest of her cranial nerve examination was normal, particularly cranial nerves
IX, $\mathrm{X}$ and XI. The general neurological evaluation was also unremarkable.

Magnetic resonance imaging (MRI), (Figure 1), revealed a mass lesion in the right hypoglossal canal with low signal on T1 and high signal on proton density and $\mathrm{T} 2$ weighted images. There was uniform enhancement of the lesion with gadolinium. These findings were consistent with the pre-operative diagnosis of a nerve sheath tumor.

The patient underwent a right retrosigmoid craniectomy. The intradural component of the lesion at the hypoglossal foramen was minimal in extent.

The microdissection was therefore directed toward the hypoglossal canal extracranially where the lesion was biopsied and partially removed. The lesion was very vascular and diffusely involved the hypoglossal nerve beyond the limits of its canal.

The hypoglossal nerve was poorly defined. In addition, electrical stimulation within the mass led to contraction of the trapezius suggesting accessory nerve involvement.

In the postoperative period, the patient continued to display right

From the Division of Neurosurgery, Department of Surgery, and Department of Pathology, Dalhousie University, Halifax, Nova Scotia, Canada

ReCeived OCtober 30, 2001. ACCEPTED IN FinAL FORM DeCEMbER 13, 2001. Reprint requests to: Renn Holness, QE II Health Sciences Centre, Division of Neurosurgery, 1796 Summer Street, Halifax, Nova Scotia B3H 3A7 


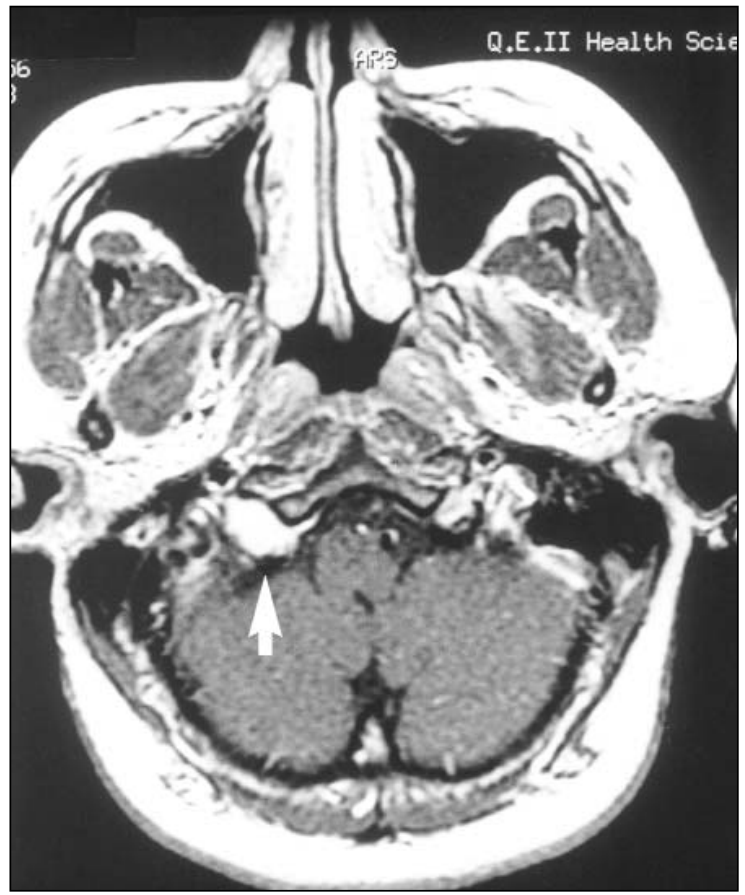

Figure 1a: Axial T1-weighted magnetic resonance image enhanced with gadolinium showing mass occupying the right hypoglossal canal (arrow).

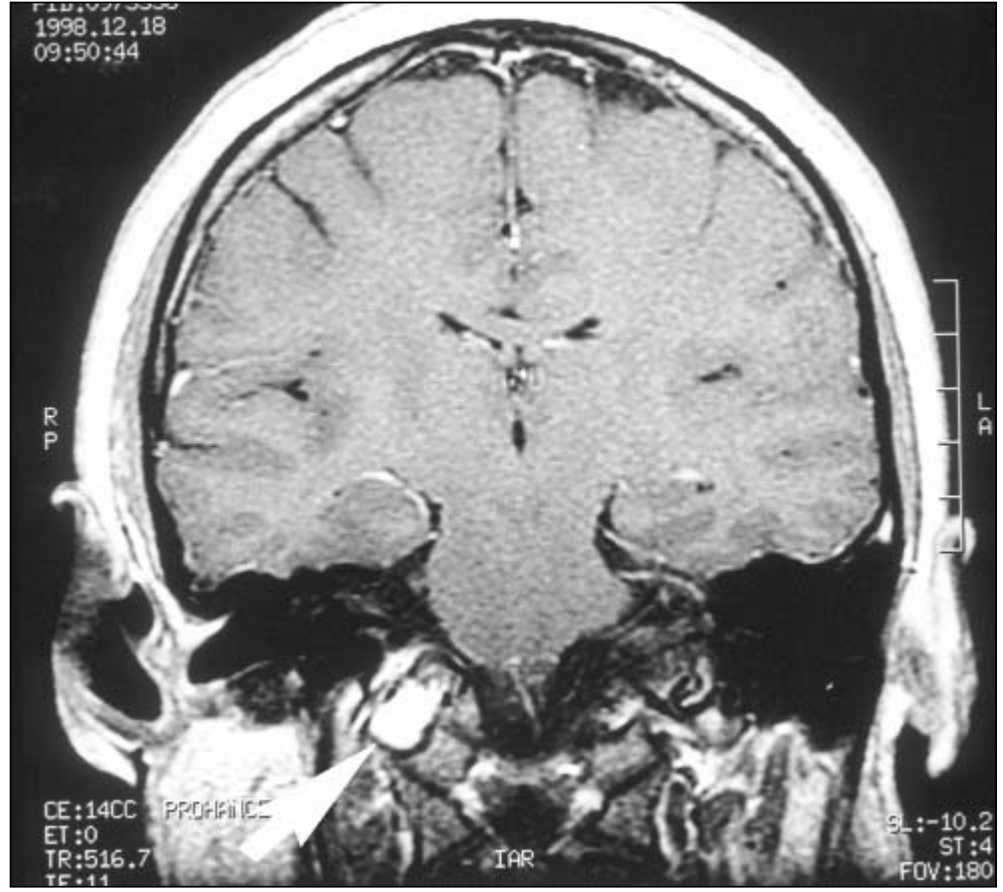

Figure 1b: Enhanced coronal T1-weighted image illustrating right hypoglossal canal lesion (arrow). hypoglossal nerve palsy as well as a new but mild spinal accessory nerve palsy.

Pathological examination of the tissue revealed a vascular lesion composed of mainly collapsed large vascular spaces lined by normal endothelial cells separated by intervening fibrous collagenous connective tissue stroma (Figure 2). Reticulin and CD34 (specific for endothelium) stains further delineated the vascular structure of the lesion. These observations were consistent with the histological diagnosis of a cavernous malformation.

By the third month postoperatively, the patient's accessory nerve palsy had disappeared. There has been minor improvement of her hypoglossal palsy two years postoperatively. Repeat MRI one and two years after surgery showed a persistent but smaller abnormality in the distal hypoglossal canal with high signal on T2 weighted images.

\section{DiscuSsion}

Cavernous malformations of the cranial nerves are rare. They have been described in association with cranial nerves II, III, VII and VIII. ${ }^{3-12}$ Although other types of vascular malformations, such as arteriovenous malformations and cryptic angiomas, have been associated with cranial nerves IV and $\mathrm{V}$, true cavernous malformations have not been reported. ${ }^{13-14}$ A Medline review of the literature did not find any previously reported case of a cavernous malformation involving the hypoglossal nerve.

The most commonly reported cranial nerve associated with cavernous malformation is the facial nerve. In their review of the literature, Dufour et $\mathrm{al}^{4}$ noted 48 cases and added six of their own. These lesions have been said to represent $0.7 \%$ of all temporal bone tumors. ${ }^{5}$ However, this may be an overestimation because some of these malformations may be arteriovenous malformations or venous angiomas instead of true cavernous malformations. Facial nerve cavernous malformations occur in one of two locations, a) in the internal auditory canal (IAC) and in the geniculate ganglion. ${ }^{4}$ They seem to affect these locations preferentially because of the intense vascularization seen in these areas. It is thought that some of the IAC cavernous malformations are actually vestibular in site, in association with the vascular plexus surrounding Scarpa's ganglion. ${ }^{5}$

As would be expected, cavernous malformations of the geniculate ganglion present with facial paralysis while those of the IAC present with hearing loss. The latter group can be differentiated from intra-canalicular vestibular schwannomas by the tendency of facial nerve dysfunction to occur while the tumor is still small. ${ }^{4}$ Computed tomography (CT) is more sensitive for early diagnosis of geniculate ganglion lesions while MRI is the imaging modality of choice for lesions of the IAC. ${ }^{5}$

The next most common cranial nerve involved by cavernous malformation is the optic nerve/chiasm complex. These lesions usually present with visual field and visual acuity deficits. Sudden acute onset of these symptoms associated with intralesional bleeding, or "apoplexy", is the usual mode of presentation. ${ }^{6}$ They are often hyperdense lesions on CT with slight or no contrast enhancement. Complete resection is often possible. $^{6-8}$

The oculomotor nerve has also been reported to be associated with a true cavernous malformation. In the four reported cases, two presented in patients with Roberts syndrome..$^{9,10,12,15}$ This is an autosomal recessive disorder characterized by symmetric 

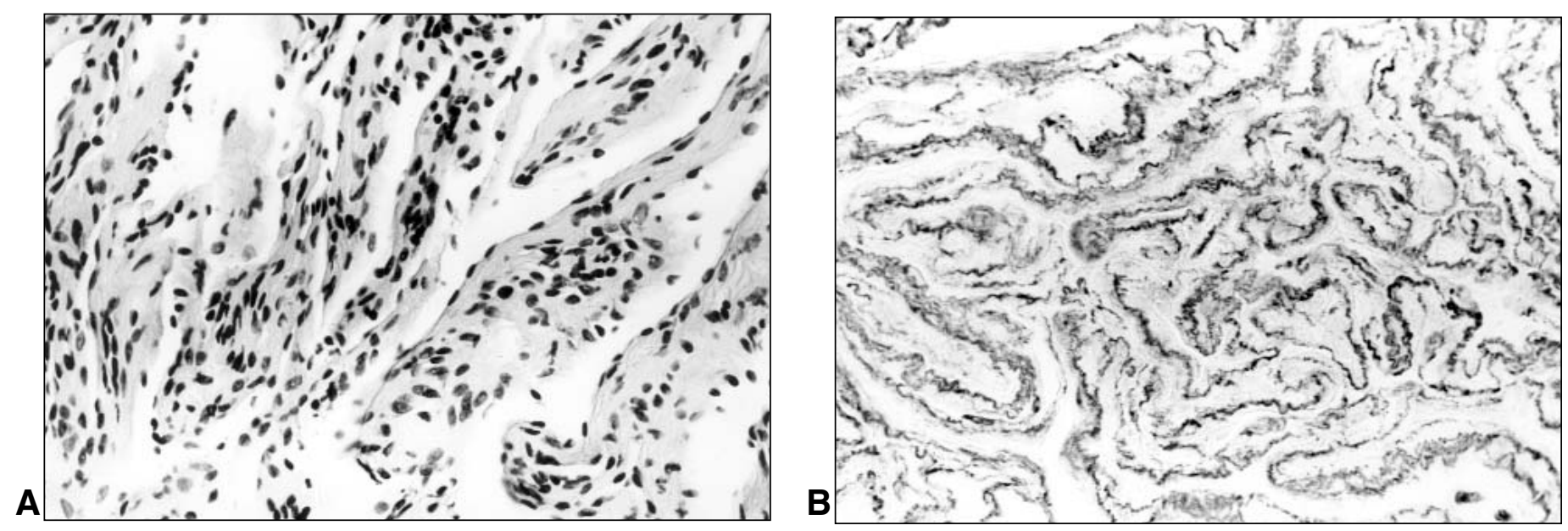

Figure 2: Photomicrograph of specimen showing partially collapsed sinusoidal spaces lined by a single layer of endothelium. A) $H$ \& $E$ stain, original magnification $\times 125$. B) CD34 stain (endothelial cell marker), original magnification x 125.

reductive limb malformations, growth retardation, esotropia and other eye abnormalities, an elongated face with a high forehead and extensive cutaneous hemangiomas.

The imaging characteristics of cranial nerve associated cavernous malformations include an isodense or hyperdense appearance on CT with variable contrast enhancement. ${ }^{6-10}$ A CT was not done on our patient; however, on MRI the lesion was hypointense on $\mathrm{T} 1$ and hyperintense on $\mathrm{T} 2$. There was uniform enhancement with gadolinium. In the few reports describing the MRI appearance of cranial nerve associated cavernous malformations, there appears to be greater variability in their imaging characteristics. On T1, these lesions may appear hypointense or show mixed high and low signal with variable enhancement. Similarly, on T2, lesions have been noted to be high or low signal depending on the acuity of the bleeding. ${ }^{7,10,16}$

Interestingly, the normal hypoglossal canal shows a characteristic symmetric enhancement pattern thought to be secondary to the presence of multiple emissary venous radicles. ${ }^{17}$ However, our patient's MRI does not resemble this previously reported pattern.

In the majority of cases, cavernous malformations of the cranial nerves have been completely resected, often with part of the associated nerve itself. ${ }^{6-10}$ Nerve grafting may or may not be feasible. In our case, the hypoglossal nerve could not be accurately defined even under magnification as the lesion diffusely involved the nerve and likely also the spinal accessory nerve at the skull base. In our judgment this considerably reduced the likelihood of successful repair of these two cranial nerves after radical resection of the malformation.

The differential diagnosis of an isolated mass lesion within the hypoglossal canal includes: hypoglossal nerve sheath tumors, ${ }^{18,19}$ meningiomas, metastases, ${ }^{20}$ myeloma $^{21}$ and extremely rare lesions such as inflammatory granulomas ${ }^{22}$ and lymphoproliferative lesions. ${ }^{23}$ Among these, schwannomas are by far the most common. In a recent review, Sato et $\mathrm{al}^{19}$ found 46 patients previously reported in the literature. Median age at diagnosis was 46 and $74 \%$ of the patients were female. The most common symptom or sign was a hypoglossal palsy, occurring in 93.5\% of cases. However, there were significant numbers of patients with other symptoms and signs including: other lower cranial nerve palsy (50\%), cerebellar signs (47.8\%), occipital and nuchal pain $(54.3 \%)$, motor signs $(41.3 \%)$ and sensory signs $(37.0 \%){ }^{19}$

\section{REFERENCES}

1. McCormick PC, Michelson WJ. Management of intracranial cavernous and venous malformations. In: Barrow DL, ed. Intracranial Vascular Malformations. Park Ridge: AANS, 1990:197-217.

2. Martin N, Vinters H. Pathology and grading of intracranial malformations. In: Barrow DL, ed. Intracranial Vascular Malformations. Park Ridge: AANS, 1990:1-30.

3. Asaoka K, Sawamura Y, Tada M, Abe H. Hemifacial spasm caused by a hemangioma at the geniculate ganglion: case report. Neurosurgery 1997; 41:1195-1197.

4. Dufour JJ, Michaud LA, Mohr G, Pouliot D, Picard C. Intratemporal vascular malformations (angiomas): particular clinical features. J Otolaryngol 1994; 23:250-253.

5. Escada P, Capucho C, Silva JM, et al. Cavernous hemangioma of the facial nerve. J Laryngol Otol 1997; 111:858-861.

6. Ferreira NP, Ferreira MP. Optic nerve apoplexy caused by a cavernous angioma: case report. Neurosurgery 1992; 30:262-264.

7. Hassler W, Zentner J, Petersen D. Cavernous hemangioma of the optic nerve. Surg Neurol 1989; 31:444-447.

8. Maruoka N, Yamakawa Y, Shimauchi M. Cavernous hemangioma of the optic nerve. J Neurosurg 1988; 69:292-294.

9. Matias-Guiu X, Alejo M, Sole T, et al. Cavernous angiomas of the cranial nerves. J Neurosurg 1990; 73:620-622.

10. Ogilvy CS, Pakzaban P, Lee JM. Oculomotor nerve cavernous angioma in a patient with Roberts syndrome. Surg Neurol 1993; 40:39-42.

11. Shibuya M, Baskaya MK, Saito K, et al. Cavernous malformations of the optic chiasm. Acta Neurochir Wien 1995; 136:29-36.

12. Yamada T, Nishio S, Matsunaga M, Fukui M, Takeshita I. Cavernous hemangioma in the oculomotor nerve. J Neurol 1986; 233:63-64.

13. Sindou M, Gilg A, Vighetto A, Jouvet A. Cryptic angioma in the trochlear nerve. Excision of the invaded portion and successful repair with an autologous graft: case report. Neurosurgery 1992; 30:255-258. 
14. Tsubaki S, Fukushima T, Tamagawa T, et al. Parapontine trigeminal cryptic angiomas presenting as trigeminal neuralgia. J Neurosurg 1989; 71:368-374.

15. Scott RM. Third nerve palsy in a 14-year old boy due to cavernous angioma of the third nerve. In: Raimondi AJ, ed. Concepts in Pediatric Neurosurgery - 3. New York: Karger, 1983, 100-107.

16. Arrue P, Thorn-Kany M, Vally P, et al. Cavernous hemangioma of the intracranial optic pathways: CT and MRI. J Comput Assist Tomogr 1999; 3:357-361.

17. Voyvodic F, Whyte A, Slavotinek J. The hypoglossal canal: normal MR enhancement pattern. AJNR 1994; 16:1707-1710.

18. Berger MS, Edwards MS, Bingham WG. Hypoglossal neurilemoma: case report and review of the literature. Neurosurgery 1982; 10:617-620.

19. Sato M, Kanai N, Fukushima Y, et al. Hypoglossal neurinoma extending intra- and extracranially: case report. Surg Neurol 1996; 45:172-175.

20. Shiraishi T, Yanagida H, Takada K, Yasuhara Y. Unusual cranial metastases from hepatoma presenting as isolated unilateral hypoglossal nerve paresis - case report. Neurol Med Chir Tokyo 1992; 32:166-168.

21. Forrett-Kaminsky MC, Scherer C, Platini C, Boujan F. Isolated paralysis of the great hypoglossal nerve disclosing multiple myeloma. Rev Neurol Paris 1991; 147:238-239.

22. Nakagawa K, Sakaki S, Fukui K, Sadamoto K. Intracranial nonspecific inflammatory granuloma. Surg Neurol 1990; 33:221225.

23. Takaki S, Kuratsu J, Mihara Y, et al. Lymphoproliferative lesion of the hypoglossal nerve: case report. Neurosurgery 1991; 28:612616. 